\title{
Improved Trends in the Mortality-To-Incidence Ratios for Liver Cancer in Countries With High Development Index and Health Expenditures
}

\section{Chi-Chih Wang}

Division of Gastroenterology and Hepatology, Department of Internal Medicine, Chung Shan Medical University Hospital

\section{Hsin-Hung Chen}

School of Medicine, Chung Shan Medical University

Wen-Wei Sung

School of Medicine, Chung Shan Medical University

Ming-Chang Tsai ( $\nabla$ tmc1110@yahoo.com.tw)

Division of Gastroenterology and Hepatology, Department of Internal Medicine, Chung Shan Medical University Hospital

\section{Research Article}

Keywords: liver cancer, mortality, incidence, mortality-to-incidence ratio, expenditure

Posted Date: February 2nd, 2021

DOI: https://doi.org/10.21203/rs.3.rs-155703/v1

License: (c) (i) This work is licensed under a Creative Commons Attribution 4.0 International License. Read Full License 


\section{Abstract}

Primary liver cancer is one of leading causes of death globally. Liver cancer has the uniqueness of geographical distribution as it predisposes viral infection etiologies and aging effects. We speculate if the human development index (HDI), current health expenditure (CHE) per capita, and current health expenditure on gross domestic product (CHE/GDP) can affect the incidence numbers, mortality numbers, or mortality-to-incidence ratios (MIRs) of liver cancer worldwide. Data was obtained from GLOBOCAN health data and statistics from the World Health Organization. MIRs and the changes in MIR over time ( $\delta \mathrm{MIR})$ were used to evaluate the correlation of expenditures on healthcare and the HDI disparities via Spearman's rank correlation coefficient. The incidence and mortality of crude rate have significant associations with HDI, CHE per capita, and CHE/GDP. Specifically, there were significant associations between $\delta \mathrm{MIR}$ and HDI as well as between $\delta \mathrm{MIR}$ and CHE per capita. However, there were no significant associations between $\delta \mathrm{MIR}$ and CHE/GDP. We evidenced that favorable liver cancer $\delta$ MIR was not associated with $\mathrm{CHE} / \mathrm{GDP}$, although it had significant association with HDI and CHE per capita. This result is worthy of the attention of the public health system all over the world.

\section{Introduction}

Primary liver cancer is one of leading causes of death globally. In 2018, liver cancer was the sixth most commonly diagnosed cancer and the fourth leading cause of cancer death in both sexes with about 841,000 new cases and 782,000 deaths annually ${ }^{1}$. Liver cancer also has unique etiologies and a wide range of subtypes. In terms of etiology, primary liver cancer commonly results from hepatitis $B$ virus, hepatitis $C$ virus infection, alcohol use, and preexisting liver cirrhosis ${ }^{2,3}$. According to the World Health Organization (WHO) classification, this type of cancer was classified into two categories: hepatocellular carcinoma (HCC) and intrahepatic cholangiocarcinoma (ICC) ${ }^{4}$. HCC is the fourth most common cause of cancer-related death worldwide, and its risk factors include chronic hepatitis B and hepatitis $\mathrm{C}$, alcohol addiction, metabolic liver disease, and exposure to dietary toxins, such as aflatoxins and aristolochic acid $^{5}$. As for ICC, it is known as the least common form of cholangiocarcinoma and it has increased in both sexes in Europe ${ }^{6}$, with both chronic liver disease and metabolic abnormalities now recognized as risk factors for ICC ${ }^{7}$.

The Human Development Index (HDI), which was created by the United Nations Development Programme, is a tangible indicator associated with clinical assessment. The HDI is a summary measure of a country's average level of achievement in the following major dimensions of human development: living a long and healthy life, being knowledgeable, and having a decent standard of living ${ }^{8}$. An investigation was conducted between HDI and mortality to incidence ratio for patients with existing liver cancer ${ }^{9}$. In addition to liver cancer, HDI was also utilized to examine other overall cancer condition and specific types of cancer outcomes, such as colorectal cancer, breast cancer, and prostate cancer, as well as disability and life expectancy ${ }^{10}$.

The mortality-to-incidence ratio (MIR) has been reported as a practical indicator for the evaluation of cancer care ${ }^{11,12}$. Due to primary liver cancer's unique geographical distribution, predisposing viral infection etiologies, and aging effects, we speculated whether HDI, current health expenditure per capita, and current health expenditure on gross domestic product would affect the incidence numbers, mortality numbers, or the MIRs of liver cancer worldwide. Since this relationship has not been fully clarified yet, we carried out this study to enrich knowledge of the incidence numbers, mortality numbers, MIRs, and MIR differences between years of primary liver cancer.

\section{Results}

\section{Epidemiology of liver cancer according to the regions}

The total number of new cases was 792,031 and number of deaths was 727,661 during this survey (Table 1 ). In both new cases and deaths, Asia had the highest cumulative risk of 12.8 new cases per 100,00 people and 11.8 deaths per 100,000 
people. On the contrary, Africa had the lowest cumulative risk of 4.9 and 4.8 per 100,000 people for new cases and deaths, respectively. In terms of mortality-to-incidence ratio, Africa had the highest of 0.98 and North America has the lowest of 0.77 .

Table 1

Summary of the number, crude rank, age-standardized rate and mortality-to-incidence ratio of liver cancer according to the regions.

\begin{tabular}{|llllllll|}
\hline & New cases & \multicolumn{3}{c}{ Deaths } & & MIR \\
\cline { 1 - 7 } Region & Number & CR & ASR & Number & CR & ASR & \\
\hline Africa & 63186 & 4.9 & 8.1 & 61962 & 4.8 & 8.0 & 0.98 \\
\hline Asia & 578027 & 12.8 & 10.9 & 533364 & 11.8 & 10.0 & 0.92 \\
\hline Europe & 73469 & 10.1 & 4.9 & 65993 & 9.1 & 4.1 & 0.90 \\
\hline Latin America and the Caribbean & 34209 & 5.3 & 4.6 & 32376 & 5.0 & 4.4 & 0.94 \\
\hline North America & 39416 & 11.1 & 6.5 & 30714 & 8.6 & 4.6 & 0.77 \\
\hline Oceania & 3724 & 9.2 & 6.7 & 3252 & 8.0 & 5.5 & 0.87 \\
\hline
\end{tabular}

\section{Epidemiology and parameters of the development and health expenditure of liver cancer of the selected countries}

The HDI ranged from 0.377 in Chad to 0.954 in Norway (Table 2). Per capita of current health expenditure ranged from 20 in Congo to 9818 in Switzerland. GDP percentage of current health expenditure ranged from $2.5 \%$ in South Sudan to $18.3 \%$ in Sierra Leone. In terms of the crude rates of incidence and mortality, Mongolia and Thailand had the first and second highest rates, respectively, and Nepal and Morocco had the first and second lowest rates, respectively. With regard to the ASR of incidence and mortality, Mongolia had the highest rates of 90.0 in incidence and 71.8 in mortality, while Morocco and Nepal both had the lowest incidence and mortality rates of 1.1 and 1.0, respectively. As for the $\delta \mathrm{MIR}$, Cuba had the highest at 0.22 and Portugal had the lowest at -0.09 . We further analyzed the association between the crude rate of incidence/mortality and HDI, CHE per capita, USD, or CHE/GDP. The incidence/mortality of crude rate had significant associations with $\mathrm{HDI}, \mathrm{CHE}$ per capita, and CHE/GDP (Fig. 1). 
Table 2

Summary of human development index, current health expenditure, cancer incidence, cancer mortality, and mortality-toincidence ratio in liver cancer of selected countries with incidence number $>923$, the mean of all countries $(n=55)$.

\begin{tabular}{|c|c|c|c|c|c|c|c|c|c|c|c|c|}
\hline \multirow[b]{2}{*}{ Country } & \multirow[t]{2}{*}{ HDI } & \multicolumn{2}{|c|}{$\begin{array}{l}\text { Current Health } \\
\text { Expenditure }\end{array}$} & \multicolumn{3}{|c|}{ Incidence } & \multicolumn{3}{|l|}{ Mortality } & \multicolumn{3}{|c|}{$\begin{array}{l}\text { Mortality-to-incidence } \\
\text { Ratio }\end{array}$} \\
\hline & & $\begin{array}{l}\text { Per } \\
\text { Capita }\end{array}$ & $\begin{array}{l}\% \text { of } \\
\text { GDP }\end{array}$ & Number & CR & ASR & Number & CR & ASR & $\begin{array}{l}\text { MIR, } \\
2012\end{array}$ & $\begin{array}{l}\text { MIR, } \\
2018\end{array}$ & dMIR \\
\hline Argentina & 0.830 & 998 & 6.8 & 2074 & 4.7 & 3.4 & 1850 & 4.2 & 3.0 & 1.07 & 0.89 & 0.18 \\
\hline Australia & 0.938 & 4934 & 9.4 & 2231 & 9.2 & 5.5 & 2020 & 8.3 & 4.5 & 0.93 & 0.90 & 0.03 \\
\hline Austria & 0.914 & 4536 & 10.3 & 994 & 11.7 & 5.2 & 821 & 9.6 & 4.1 & 0.94 & 0.82 & 0.12 \\
\hline Bangladesh & 0.614 & 32 & 2.6 & 2940 & 1.8 & 2.1 & 2730 & 1.6 & 2.0 & 0.95 & 0.89 & 0.06 \\
\hline Brazil & 0.761 & 780 & 8.9 & 11256 & 5.4 & 4.4 & 10673 & 5.1 & 4.1 & 1.04 & 0.94 & 0.10 \\
\hline Burkina Faso & 0.434 & 33 & 5.4 & 1289 & 6.5 & 13.6 & 1262 & 6.4 & 13.3 & 0.97 & 0.98 & -0.01 \\
\hline C?te d'Ivoire & 0.516 & 75 & 5.4 & 1110 & 4.5 & 8.1 & 1119 & 4.5 & 8.2 & 0.95 & 1.00 & -0.05 \\
\hline Cambodia & 0.581 & 70 & 6.0 & 2474 & 15.3 & 20.8 & 2473 & 15.3 & 20.8 & 0.96 & 1.00 & -0.04 \\
\hline Canada & 0.922 & 4508 & 10.4 & 3534 & 9.8 & 5.1 & 3275 & 9.1 & 4.2 & 1.02 & 0.93 & 0.09 \\
\hline Chile & 0.847 & 1102 & 8.1 & 1387 & 7.7 & 5.0 & 1261 & 7.0 & 4.5 & 1.11 & 0.91 & 0.20 \\
\hline China & 0.758 & 426 & 5.3 & 378016 & 26.8 & 17.7 & 352962 & 25.0 & 16.4 & 0.97 & 0.93 & 0.04 \\
\hline Congo & 0.459 & 20 & 4.3 & 3519 & 4.2 & 7.5 & 3530 & 4.2 & 7.7 & 0.92 & 1.00 & -0.08 \\
\hline Czechia & 0.891 & 1284 & 7.3 & 959 & 9.2 & 3.9 & 772 & 7.4 & 3.0 & 0.76 & 0.80 & -0.04 \\
\hline Egypt & 0.700 & 157 & 4.2 & 24724 & 25.0 & 31.2 & 24420 & 24.6 & 30.8 & 0.95 & 0.98 & -0.03 \\
\hline Ethiopia & 0.470 & 24 & 4.0 & 1574 & 1.5 & 2.6 & 1622 & 1.5 & 2.7 & 0.92 & 1.00 & -0.08 \\
\hline France & 0.891 & 4026 & 11.1 & 9525 & 15.1 & 7.6 & 8223 & 13.0 & 5.9 & 0.97 & 0.86 & 0.11 \\
\hline Germany & 0.939 & 4592 & 11.2 & 7974 & 10.0 & 4.1 & 7467 & 9.3 & 3.5 & 0.84 & 0.93 & -0.09 \\
\hline Ghana & 0.596 & 80 & 5.9 & 2681 & 9.1 & 14.6 & 2665 & 9.1 & 14.6 & 0.97 & 1.00 & -0.03 \\
\hline Guatemala & 0.651 & 224 & 5.7 & 1627 & 9.5 & 13.9 & 1585 & 9.2 & 13.6 & 0.96 & 0.97 & -0.01 \\
\hline Guinea & 0.466 & 25 & 4.5 & 1573 & 12.1 & 21.5 & 1404 & 10.8 & 19.2 & 0.95 & 0.89 & 0.06 \\
\hline Hungary & 0.845 & 894 & 7.2 & 1012 & 10.7 & 5.2 & 847 & 8.9 & 4.2 & 0.98 & 0.83 & 0.15 \\
\hline India & 0.647 & 63 & 3.9 & 26651 & 2.0 & 2.1 & 24749 & 1.8 & 2.0 & 0.95 & 0.90 & 0.05 \\
\hline Indonesia & 0.707 & 112 & 3.3 & 17890 & 6.7 & 7.2 & 17572 & 6.6 & 7.1 & 0.95 & 0.99 & -0.04 \\
\hline Iran & 0.797 & 366 & 7.6 & 3138 & 3.8 & 4.2 & 3085 & 3.8 & 4.1 & 0.95 & 1.00 & -0.05 \\
\hline Italy & 0.883 & 2700 & 9.0 & 10661 & 18.7 & 7.6 & 8490 & 14.9 & 5.3 & 0.86 & 0.80 & 0.06 \\
\hline Japan & 0.915 & 3733 & 10.9 & 26641 & 21.9 & 6.9 & 20048 & 16.5 & 4.6 & 0.90 & 0.75 & 0.15 \\
\hline Kazakhstan & 0.817 & 379 & 3.9 & 1091 & 6.0 & 5.5 & 974 & 5.3 & 4.9 & 0.95 & 0.88 & 0.07 \\
\hline Kenya & 0.579 & 70 & 5.2 & 1325 & 2.6 & 5.2 & 1310 & 2.6 & 5.2 & 0.92 & 1.00 & -0.08 \\
\hline Lao & 0.604 & 53 & 2.8 & 1008 & 14.5 & 21.5 & 1005 & 14.5 & 21.5 & 0.95 & 1.00 & -0.05 \\
\hline
\end{tabular}




\begin{tabular}{|c|c|c|c|c|c|c|c|c|c|c|c|c|}
\hline \multirow[b]{2}{*}{ Country } & \multirow[t]{2}{*}{ HDI } & \multicolumn{2}{|c|}{$\begin{array}{l}\text { Current Health } \\
\text { Expenditure }\end{array}$} & \multicolumn{3}{|c|}{ Incidence } & \multicolumn{3}{|l|}{ Mortality } & \multicolumn{3}{|c|}{$\begin{array}{l}\text { Mortality-to-incidence } \\
\text { Ratio }\end{array}$} \\
\hline & & $\begin{array}{l}\text { Per } \\
\text { Capita }\end{array}$ & $\begin{array}{l}\text { \% of } \\
\text { GDP }\end{array}$ & Number & CR & ASR & Number & CR & ASR & $\begin{array}{l}\text { MIR, } \\
2012\end{array}$ & $\begin{array}{l}\text { MIR, } \\
2018\end{array}$ & dMIR \\
\hline Malaysia & 0.804 & 386 & 4.0 & 1869 & 5.9 & 6.0 & 1851 & 5.8 & 5.9 & 1.15 & 0.98 & 0.17 \\
\hline Mexico & 0.767 & 535 & 5.9 & 6412 & 4.9 & 5.0 & 6044 & 4.7 & 4.7 & 0.95 & 0.96 & -0.01 \\
\hline Mongolia & 0.735 & 152 & 3.9 & 2182 & 70.1 & 90.0 & 1716 & 55.1 & 71.8 & 0.89 & 0.79 & 0.10 \\
\hline Mozambique & 0.446 & 28 & 5.4 & 1165 & 3.8 & 6.3 & 1138 & 3.7 & 6.4 & 0.93 & 0.97 & -0.04 \\
\hline Myanmar & 0.584 & 59 & 4.9 & 5214 & 9.7 & 9.8 & 5270 & 9.8 & 9.9 & 0.94 & 1.01 & -0.07 \\
\hline Nigeria & 0.534 & 97 & 3.6 & 5053 & 2.6 & 4.7 & 5078 & 2.6 & 4.8 & 0.97 & 1.00 & -0.03 \\
\hline Pakistan & 0.560 & 38 & 2.7 & 4280 & 2.1 & 3.0 & 4159 & 2.1 & 2.9 & 0.96 & 1.00 & -0.04 \\
\hline Peru & 0.759 & 323 & 5.3 & 2032 & 6.3 & 6.0 & 1967 & 6.1 & 5.8 & 0.98 & 0.97 & 0.01 \\
\hline Philippines & 0.712 & 127 & 4.4 & 9234 & 8.7 & 10.8 & 9096 & 8.6 & 10.6 & 0.96 & 0.99 & -0.03 \\
\hline Poland & 0.872 & 797 & 6.3 & 2252 & 6.0 & 3.1 & 1935 & 5.2 & 2.5 & 1.04 & 0.87 & 0.17 \\
\hline Portugal & 0.850 & 1722 & 9.0 & 1191 & 11.9 & 5.1 & 1178 & 11.8 & 4.9 & 0.90 & 0.99 & -0.09 \\
\hline $\begin{array}{l}\text { Russian } \\
\text { Federation }\end{array}$ & 0.824 & 524 & 5.6 & 9513 & 6.7 & 3.7 & 10282 & 7.2 & 3.9 & 1.25 & 1.07 & 0.18 \\
\hline Senegal & 0.514 & 36 & 4.0 & 1060 & 6.5 & 12.2 & 1068 & 6.6 & 12.3 & 0.95 & 1.02 & -0.07 \\
\hline Singapore & 0.935 & 2280 & 4.3 & 1206 & 21.1 & 11.1 & 1128 & 19.7 & 10.2 & 0.98 & 0.93 & 0.05 \\
\hline South Korea & 0.906 & 2013 & 7.4 & 15687 & 31.1 & 16.8 & 10978 & 21.7 & 11.0 & 0.73 & 0.70 & 0.03 \\
\hline Spain & 0.893 & 2354 & 9.2 & 5822 & 13.0 & 6.2 & 4518 & 10.1 & 4.4 & 0.82 & 0.78 & 0.04 \\
\hline Tanzania & 0.528 & 32 & 6.1 & 1483 & 2.5 & 4.7 & 1462 & 2.5 & 4.7 & 1.00 & 1.00 & 0.00 \\
\hline Thailand & 0.765 & 217 & 3.8 & 22051 & 32.2 & 20.3 & 21900 & 32.0 & 20.2 & 0.95 & 0.99 & -0.04 \\
\hline Turkey & 0.807 & 455 & 4.1 & 4044 & 5.0 & 4.2 & 3989 & 4.9 & 4.1 & 0.93 & 0.98 & -0.05 \\
\hline Uganda & 0.528 & 46 & 7.3 & 1793 & 4.1 & 7.4 & 1534 & 3.5 & 6.6 & 0.95 & 0.85 & 0.10 \\
\hline Ukraine & 0.750 & 125 & 6.1 & 1714 & 4.0 & 2.2 & 2106 & 4.9 & 2.6 & 1.06 & 1.23 & -0.17 \\
\hline $\begin{array}{l}\text { United } \\
\text { Kingdom }\end{array}$ & 0.920 & 4356 & 9.9 & 6458 & 10.0 & 4.7 & 5415 & 8.4 & 3.6 & 0.97 & 0.84 & 0.13 \\
\hline $\begin{array}{l}\text { United } \\
\text { States of } \\
\text { America }\end{array}$ & 0.920 & 9536 & 16.8 & 35868 & 11.2 & 6.7 & 27430 & 8.6 & 4.7 & 0.80 & 0.77 & 0.03 \\
\hline Uzbekistan & 0.710 & 134 & 6.2 & 1352 & 4.2 & 5.2 & 1195 & 3.7 & 4.6 & 0.97 & 0.88 & 0.09 \\
\hline Venezuela & 0.726 & 973 & 3.2 & 1077 & 3.3 & 3.3 & 1039 & 3.2 & 3.2 & 0.94 & 0.97 & -0.03 \\
\hline Viet Nam & 0.693 & 117 & 5.7 & 24493 & 25.7 & 22.9 & 24571 & 25.7 & 22.9 & 0.95 & 1.00 & -0.05 \\
\hline
\end{tabular}




\section{The association between MIR and $\delta$ MIR and parameters of the development and health expenditure of the selected countries}

We analyzed the associations between MIR or $\delta$ MIR and HDI, CHE per capita, or CHE/GDP (Fig. 2, 3). MIR had significant associations with HDI ( $\rho:-0.523, p<0.001)$, CHE per capita $(\rho:-0.534, p<0.001)$, and CHE/GDP $(\rho:-0.284, p=0.003)$. Moreover, there are significant associations between $\delta$ MIR and HDI $(\rho: 0.452, p<0.001)$ or CHE per capita $(\rho: 0.450, p<$ 0.001), except the $\delta$ MIR to CHE/GDP ( $\rho: 0.177, p=0.063)$.

\section{Discussion}

Primary liver cancer has unique geographical distribution and predisposing viral infection etiologies, which comprises HCC and ICC. HCC is the most common type, with hepatitis B, hepatitis C, alcohol use, and preexisting liver cirrhosis being the most important risk factors ${ }^{1}$. Furthermore, the incidence of HCC generally follows the geographical distribution of hepatitis $B$, hepatitis $C$ virus, liver cirrhosis, and increasing prevalence among patients with nonalcoholic fatty liver disease ${ }^{2}$. This indicates that a region with risk factors for $\mathrm{HCC}$ would be the region with a high incidence of primary liver cancer. Although HCC typically occurs in adults, $0.5 \%-1 \%$ of cases are reported to occur in patients less than 20 years old ${ }^{3}$. It is the second most common (20\%) primary liver malignancy in adolescents and most commonly affects children between 10 to 19 years old $^{4}$. Specifically, children in Asian countries are 10 times more likely than children ${ }^{1}$ in North America to perinatally acquire hepatitis $\mathrm{B}$ infection ${ }^{5}$. Although treatments for liver cancer have improved gradually, primary liver cancer is still one of the leading causes of cancer death annually ${ }^{6}$.

In order to elucidate the associations between incidence/mortality of liver cancer and development within countries, we considered whether HDI, CHE per capita, and CHE/GDP influence the incidence numbers, mortality numbers, MIRs, and $\delta$ MIR of liver cancer worldwide.

Countries with higher development and health expenditures have higher incidence rates, and this statistic is possibly due to the wide implementation of early cancer screening systems ${ }^{7}$. The higher the HDI, current health expenditure, and CHE/GDP are, the higher the incidence of crude rate will be $(p<0.001, p<0.001, p=0.002$ Fig. 1A, 1C, 1E respectively).

On the contrary, countries with higher HDI, CHE per capita and CHE/GDP have lower mortality rates $(p<0.001, p<0.001, p=$ 0.004 Fig. 1B, 1D, 1F respectively). This suggests that a country may have a better health care system, which results in an increased elderly population and increased incidence and mortality rates in cancer patients ${ }^{8}$. Therefore, MIR-which is a practical indicator for the evaluation of cancer care-is inversely proportional to HDI, CHE per capita, and CHE/GDP based on our analysis (Fig. 2).

Additionally, there are significant associations between $\delta \mathrm{MIR}$ and HDI as well as CHE per capita (Fig. 3A and 3B). However, the $\delta$ MIR had no significant correlation with CHE/GDP (Fig. 3C). This indicates that a country with higher CHE/GDP does not affect the outcomes of $\delta \mathrm{MIR}$ for liver cancer in years. It is worth to note that valuables of $\delta \mathrm{MIR}$ result from the difference between valuables in 2012 and those in 2018 in each country.

There are some limitations in our study. For example, our results were calculated from the WHO database and any errors in the primary data would have influenced our secondary database study. Secondly, the use of the HDI, CHE per capita, and $\mathrm{CHE} / \mathrm{GDP}$ to represent the healthcare disparities would be a major limitation itself. In future studies, other additional factors should be investigated.

We evidenced that favorable liver cancer $\delta \mathrm{MIRs}$ are not associated with CHE/GDP, although it has a significant relationship with HDI and CHE per capita. This result is worth the attention of the public health system all over the world. 


\section{Methods}

Liver cancer, ICD-10 C22, and epidemiological data were obtained from the online Global Cancer Observatory (GLOBOCAN) 2012 and 2018 database. HDI data were obtained from the online United Nations Development Programme, Human Development Report Office. Data on health expenditures, including the CHE per capita and CHE/GDP, were obtained from the WHO Statistics online database.

The MIR was defined as the ratio of the crude rate (CR) of mortality to the CR of incidence ${ }^{13-16}$. The exclusion criteria for country selection were based on the missing data in the WHO statistics $(\mathrm{N}=12)$, on the missing HDI data $(\mathrm{N}=2)$, on the unavailability of calculable MIR ( $=3)$, on the MIR outliers $(N=19)$, and incidence less than 200 per 100,000. A total of 111 countries were included in the final analysis. The $\delta$ MIR was defined as the difference between the MIR in 2012 and in 2018 $(\delta \mathrm{MIR}=\mathrm{MIR} \text { [in 2012] }-\mathrm{MIR} \text { [in 2018] })^{17}$. Associations among the MIR, $\delta \mathrm{MIR}$, and other factors in various countries were estimated using Spearman's rank correlation coefficient by using the SPSS statistical software version 15.0 (SPSS, Inc., Chicago, IL). $P$ values of $<0.05$ were considered statistically significant. Scatterplots were generated with Microsoft Excel.

\section{Declarations}

\section{Author contributions}

Chi-Chih Wang and Ming-Chang Tsai conceived and supervised the study. Chi-Chih Wang and Hsin-Hung Chen collected data. Wen-Wei Sung performed statistical analyses and prepared figures. Hsin-Hung Chen and Wen-Wei Sung wrote the first draft manuscript. Ming-Chang Tsai reviewed and edited the manuscript.

\section{Additional Information}

The authors declare that they have no competing interests.

\section{References}

1. Bray, F. et al. Global cancer statistics 2018: GLOBOCAN estimates of incidence and mortality worldwide for 36 cancers in 185 countries. CA: a cancer journal for clinicians. 68, 394-424 (2018).

2. Akinyemiju, T. et al. The burden of primary liver cancer and underlying etiologies from 1990 to 2015 at the global, regional, and national level: results from the global burden of disease study 2015. JAMA oncology. 3, 1683-1691 (2017).

3. Marrero, J. A. et al. Diagnosis, staging, and management of hepatocellular carcinoma: 2018 practice guidance by the American Association for the Study of Liver Diseases. Hepatology. 68, 723-750 (2018).

4. Nagtegaal, I. D. et al. The 2019 WHO classification of tumours of the digestive system. Histopathology. $76,182-188$ (2020).

5. Yang, J. D. et al. A global view of hepatocellular carcinoma: trends, risk, prevention and management. Nature reviews Gastroenterology \& hepatology,1-16(2019).

6. Bertuccio, P. et al. A comparison of trends in mortality from primary liver cancer and intrahepatic cholangiocarcinoma in Europe. Annals of oncology. 24, 1667-1674 (2013).

7. Zhang, H., Yang, T., Wu, M. \& Shen, F. Intrahepatic cholangiocarcinoma: epidemiology, risk factors, diagnosis and surgical management. Cancer letters. 379, 198-205 (2016).

8. Larroca, S. G. T. et al. Human Development Index (HDI) of the maternal country of origin as a predictor of perinatal outcomes-a longitudinal study conducted in Spain. BMC pregnancy and childbirth. 17, 314 (2017).

9. Shao, S. Y. et al. Impact of national Human Development Index on liver cancer outcomes: Transition from 2008 to 2018. World Journal of Gastroenterology. 25, 4749 (2019). 
10. Fidler, M. M., Bray, F. \& Soerjomataram, I. The global cancer burden and human development: A review. Scandinavian journal of public health. 46, 27-36 (2018).

11. Sunkara, V. \& Hébert, J. R. The application of the mortality-to-incidence ratio for the evaluation of cancer care disparities globally. Cancer. 122, 487-488 (2016).

12. Choi, E. et al. Cancer mortality-to-incidence ratio as an indicator of cancer management outcomes in Organization for Economic Cooperation and Development countries. Epidemiology and Health39 (2017).

13. Sunkara, V. \& Hebert, J. R. The colorectal cancer mortality-to-incidence ratio as an indicator of global cancer screening and care. Cancer. 121, 1563-1569 https://doi.org/10.1002/cncr.29228 (2015).

14. Chen, S. L. et al. Prostate Cancer Mortality-To-Incidence Ratios Are Associated with Cancer Care Disparities in 35 Countries. Sci Rep. 7, 40003 https://doi.org/10.1038/srep40003 (2017).

15. Sung, W. W. et al. Favorable mortality-to-incidence ratios of kidney Cancer are associated with advanced health care systems. BMC Cancer. 18, 792 https://doi.org/10.1186/s12885-018-4698-6 (2018).

16. Wang, S. C. et al. The gender difference and mortality-to-incidence ratio relate to health care disparities in bladder cancer: National estimates from 33 countries. Sci Rep. 7, 4360 https://doi.org/10.1038/s41598-017-04083-z (2017).

17. Wang, S. C. et al. Limited improvement in prostate cancer mortality-to-incidence ratios in countries with high health care expenditures. Aging (Albany NY). 12, 21308-21315 https://doi.org/10.18632/aging.103865 (2020).

\section{Figures}


(A)

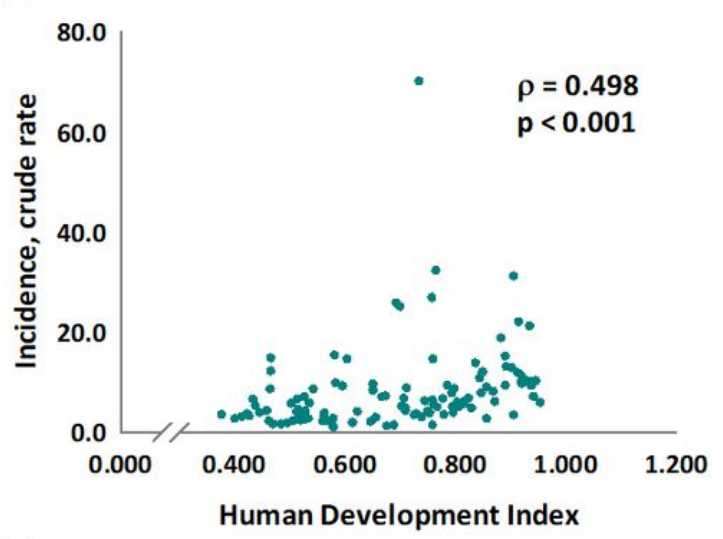

(C)

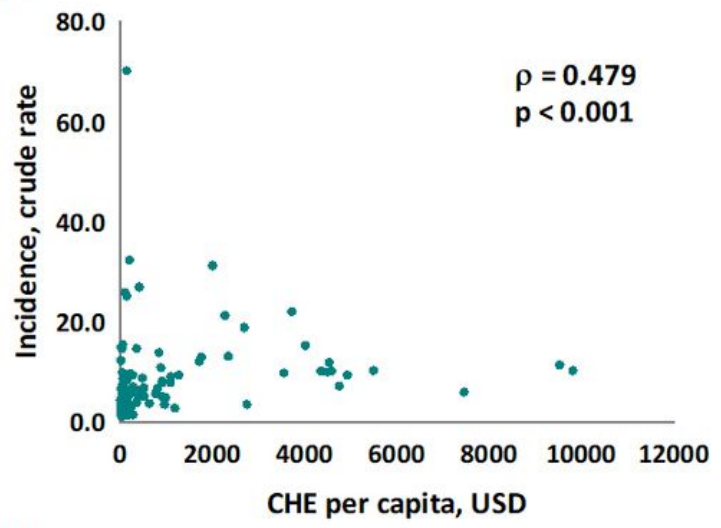

(E)

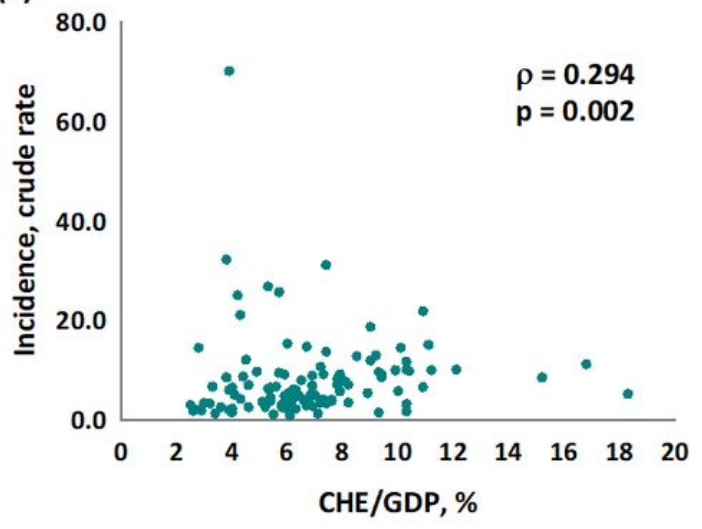

(B)

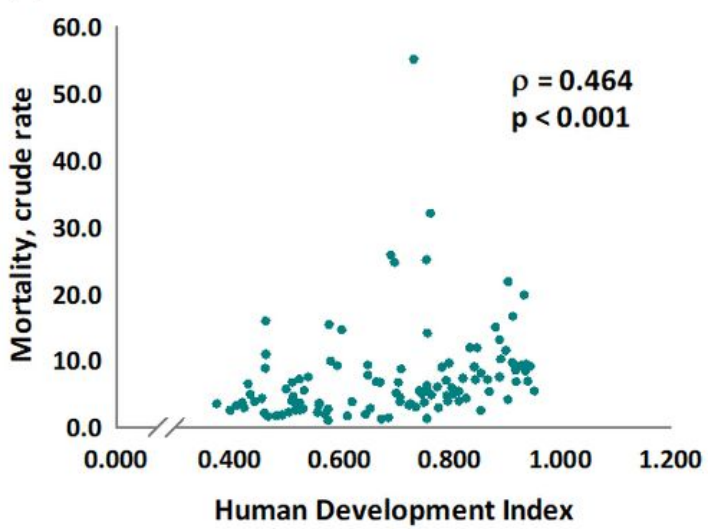

(D)

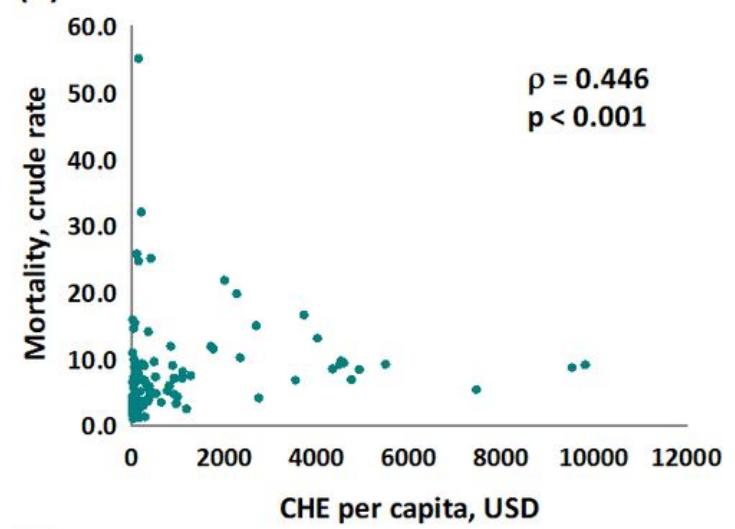

(F)

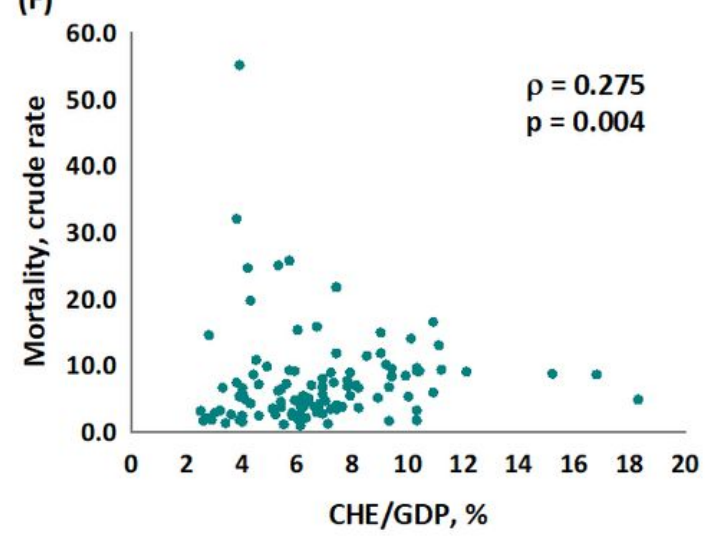

\section{Figure 1}

The association between human development index, current health expenditure and the crude rates of $(A, C$, and $E)$ incidence, and (B, D, and F) mortality in liver cancer.
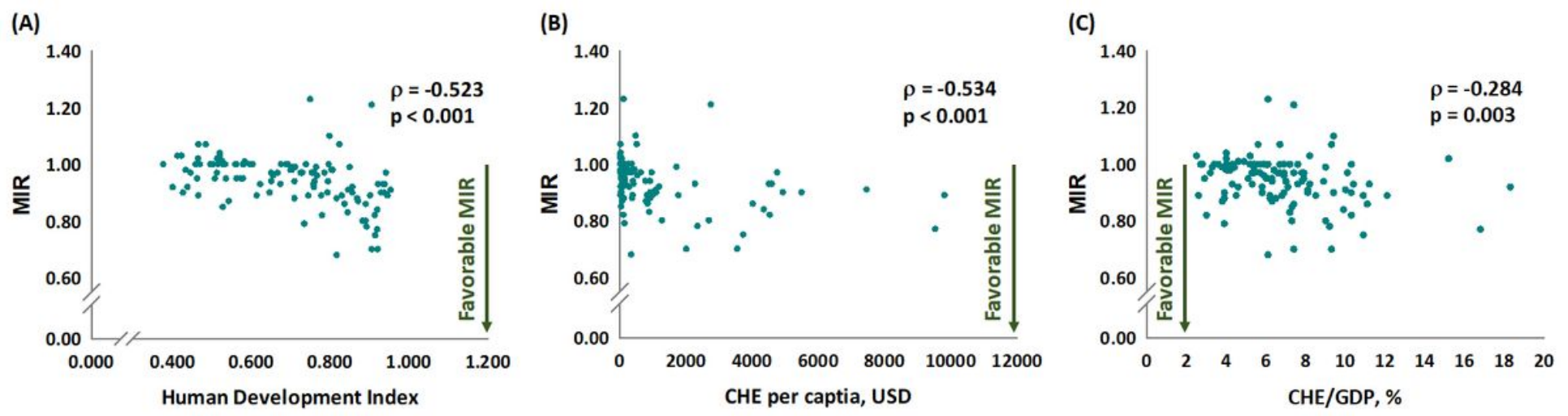


\section{Figure 2}

The (A) human development index, (B) current health expenditure per capita, and (C) current health expenditure as percentage of gross domestic product are significantly associated with mortality-to-incidence ratio in liver cancer.
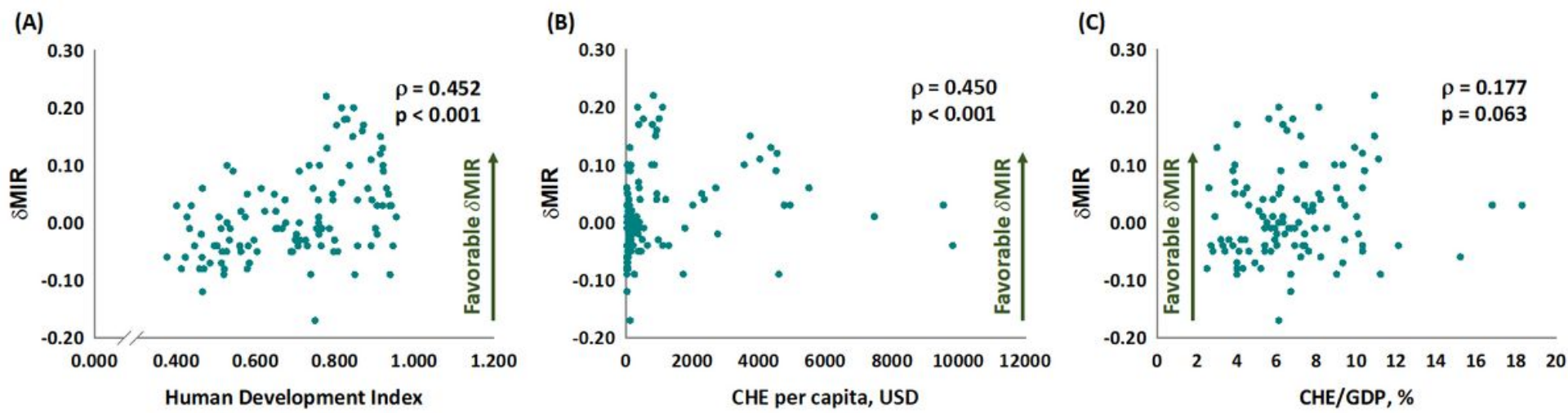

\section{Figure 3}

The (A) human development index, and (B) current health expenditure per capita are statistically associated with delta mortality-to-incidence ratio in liver cancer. The current health expenditure as percentage of gross domestic product (C) is not significantly associated with delta mortality-to-incidence ratio in liver cancer.

\section{Supplementary Files}

This is a list of supplementary files associated with this preprint. Click to download.

- liverMIRsupptable20201230.docx 